\title{
Research on CBI Teaching Mode in College English Public Course
}

\author{
Qing Song \\ School of Foreign Languages, Kunming University, Kunming, China
}

932821517@qq.com

Keywords: college English teaching, content-based instruction, teaching mode

\begin{abstract}
College English teaching in public courses should adopt the theme and content to practice two content-based instruction (CBI) teaching modes. In the process of use, attention should be paid to the necessary adjustments and reforms of the two teaching modes in the light of the specific conditions in China. In addition, colleges and universities should, according to their own characteristics, classify and systematically arrange the relevant teaching contents, teaching methods and strategies, teaching objects, and teacher resources of college English public courses to achieve the organic integration of various teaching modes.
\end{abstract}

\section{Introduction}

Content-based instruction (CBI) is content-based language teaching, also known as content teaching [1]. The basic idea is to acquire language through the use of language rather than simply using language as a learning purpose. The way to achieve this basic idea can be summarized as "combining specific themes or academic content with the purpose of language teaching, subject knowledge teaching and language teaching at the same time, enabling students to acquire information through the second language and develop language in the process skill"[2]. Since the second half of the 20th century, in Canada, the United States, and other countries, the CBI has undergone a process of continuous evolution and development, and many teaching modes have been gradually formed during the development process [3]. These countries are guided by the CBI concept and have achieved remarkable teaching achievements and social effects in language teaching [4]. The success of foreign CBI language teaching is the best affirmation of the CBI concept. It is appropriate to absorb foreign advanced teaching concepts and teaching models. Foreign use is a must, which will surely make our language teaching a new level.

\section{CBI Teaching Mode}

In general, there are five representative CBI teaching models developed by Canada, the United States, and other countries: immersive mode, protection mode, auxiliary mode, theme mode, and content drilling mode. Each model has its own specific theoretical principles and practical operating rules. It should combine the actual situation of college English teaching in our country and select the appropriate CBI model.

The CBI teaching model is closely integrated with the nature of the curriculum and teaching objectives at the beginning of development and design. Therefore, the choice of CBI teaching model should be based on the nature of the curriculum and teaching objectives. The five CBI teaching models have different degrees of emphasis on language and content, and the teaching objectives of the curriculum determine whether the curriculum focuses on language teaching or teaching on subject knowledge. It is language-oriented teaching or content-oriented teaching. The original design of the immersive mode and the protection mode is based on the content as the teaching purpose, and is applicable to the teaching of subject special courses; while the content practice and the theme mode are aimed at the language teaching, and is applicable to the CBI target language (such as English) as the main teaching goal. The auxiliary mode is characterized by the opening of two courses: "professional courses + language courses". It not only pays attention to language teaching goals, but also emphasizes professional knowledge teaching. Whether a CBI 
model can be used for the teaching of a course should be based on the premise that the model's emphasis on the content/language is matched with the teaching objectives of the course.

College English teaching is a general term. According to Tom Hutchinson \& Alan Waters' language teaching tree diagram, our theory circles are accustomed to progressively classify different stages of college English teaching to EGP, EAP and ESP. Among them, the teaching of college English public courses belongs to the category of EGP. Its teaching goal and focus are undoubtedly "language", and it does not require very profound professional knowledge of the subject. Therefore, the college English public course should adopt content exercises and topic patterns.

\section{Reference and Adjustment of Foreign CBI Teaching Mode}

In terms of language teaching, our country's specific situation is different from that of Western countries. English teaching in the United Kingdom, English teaching in France and English teaching for postgraduate students in the United States are the vast majority of teaching target languages (English/French) as a second language. The essential difference between "second language" (ESL) teaching and foreign language (EFL) teaching lies in the different context of natural teaching. ESL's natural teaching context is English. Students live in a real English social environment: English newspapers, English television, English radio, and food, clothing, transportation, etc. are all inseparable from English; in society, most people communicate in English; in schools, English teachers are native speakers of English and teaching activities are conducted in English. The natural teaching context of EFL is not English. In most regions of China, the natural teaching context of EFL is Chinese. Students live in the social environment of Chinese language: Chinese newspapers, Chinese television, Chinese radio, and Chinese are used for food, clothing, housing, and transportation. In society, using English is not necessary. In schools, English teachers use Chinese as their mother tongue to communicate with their students. All use Chinese. The CBI concept originated from the "second language" natural teaching context. The huge difference between ESL and EFL natural teaching context determines that the application of foreign CBI teaching model in China EFL teaching will face different levels of "imperfections", and the foreign CBI teaching model must be properly adjusted or transformed in order to be successfully applied. The following are the implementation rules and principles of the adjusted theme model and content drill model.

\subsection{Theme-based Instruction.}

The purpose and focus of Theme-Based Instruction (TBI) is language teaching. Its purpose is to organize teaching around a specific topic or theme related to a particular idea. Its operating mechanism is to find ways to enable students to actively participate in various thematic activities, in the process of participating in activities, through the use of language to achieve the purpose of language teaching. Language skills such as listening, speaking, reading and writing have been comprehensively used in thematic activities. Languages have been acquired through experience and practice, participation and commentary, and induction, discussion, debate, presentation, performance, and entertainment. This is different from the traditional grammatical structure-based teaching, and it is also different from language training such as listening, speaking, reading, writing, and translating. In the TBI model, the topic selection requirements are in line with the needs of students and are of great interest to the students. They may be professional knowledge or non-professional knowledge such as daily life knowledge. The teaching materials are required to be English-speaking, that is, the teaching materials are written in English. The native speaker prepares or edits the text. The article is written by a native English speaker. The video and audio recordings are recorded by native English speakers. The purpose is to provide students with authentic English pronunciation, language structure, and cultural background. The development of the TBI requires teachers to have good oral English and strong communication skills. The United States implements TBI to teach foreign students in English. Teachers use their own mother tongue and at least a second language. There is no difficulty in communicating in English. The overwhelming majority of college English public courses in China are taught by Chinese teachers who teach Chinese to 
students in English. In the vast majority of cases, teachers do not use their native language but their foreign languages. At present, although it is unrealistic to say that making English teachers in China generally meet the requirements of TBI for teachers' language quality, the vast majority of college English teachers can meet this requirement. For the sake of comprehensive consideration, it is suggested that the TBI teachers' arrangement follow the following two points: (1) The conditional institutions may hire English tutors to be responsible for the teaching of the topic mode of the English Public Lessons; (2) The combination of multiple teaching modes to arrange communication skills strong, well-spoken English teachers conduct thematic mode teaching.

\subsection{Content Training Instruction.}

Content exercises are frequently used language lessons with frequent use of content for practice. Among them, language learning is the absolute first, and content learning is secondary. Different from the theme-based instruction, which organizes teaching around a specific topic or topic related to a specific topic, the content training instruction focuses on the structure and characteristics of the language and focuses on linguistic knowledge such as grammar, vocabulary, discourse, and style. In addition, it also focuses on training in language skills such as listening, speaking, reading, writing and translating. The content of language drill teaching can be relatively fixed (at this time tends to theme mode), it can also involve multiple special fields, until the content without fixed topics is frequently converted. In short, the difference between content drills and topic patterns is that the topic pattern emphasizes the fixed nature of the content while the content drill emphasizes the fixed nature of the language structure and features.

The essence of language is to express emotions, even if the most meaningless language contains certain information content. Language and the content of the information it conveys are closely linked and inseparable. Without the content of the information to be delivered, language loses its meaning of existence. Therefore, strictly speaking, all language teaching (including the traditional grammatical structure teaching method) is based on content, but based on the content of the way and degree is different. The practice of content-based content manipulation is simpler, and content selection is more flexible. The degree of content-based content can be more concise. It can be seen that there is not much difference between content drills and traditional grammar structure teaching methods. In other words, content drills are grammatical structure teaching methods under the CBI philosophy. Therefore, the teaching arrangement of content exercises can refer to the traditional grammar structure teaching method, and the requirement for teachers' oral communication ability is not as high as that of the theme-based instruction.

\section{Organic Combination of Multiple Teaching Modes}

Language teaching practice can not always adopt a teaching mode. It is suitable for the local conditions, and a variety of teaching modes are used in combination to receive better results. College English teaching is no exception. It is confirmed that the common language teaching in college English can adopt two modes of CBI: thematic mode and content practice. It also needs to solve the problem of organic combination and integration of multiple teaching modes. This includes not only the combination of different CBI teaching modes, but also the combination of CBI teaching mode and other teaching modes. The integration of various teaching modes in the process of teaching management and teaching practice is reflected in the classification, co-ordination and systematic arrangement of teaching resources such as teaching content, teaching methods and strategies, teaching objects, and teachers according to their own characteristics.

\subsection{The Combination of Different CBI Teaching Modes.}

As far as college English teaching is concerned, the combination of CBI teaching modes mainly refers to the combination of theme mode and content practice. Topic patterns and content exercises have their own advantages and disadvantages, and they are complementary. Thematic mode focuses on the careful selection of topical content and the meticulous organization of thematic activities. It requires teachers to have a strong ability to organize activities, to master the theme of the activity 
and a good ability to communicate in spoken English; content training mode to the content selection. The requirements are not high and arbitrary. The classroom activities are simple in form. There are no specific requirements for the above three abilities of the teachers. However, the teachers are required to be familiar with the structural features of the language and can select a large number of examples for the students to use in their drills. The theme pattern requires students to be active in thinking, have basic language skills, and desire to actively participate in activities. The classroom atmosphere is easy and interesting. Students often learn languages unconsciously, and they often find it difficult to detect their own language progress. The content practice model is more suitable for students who are law-abiding and passive. Although the classroom atmosphere is sometimes monotonous and boring, students can be particularly aware of what language knowledge and skills they are learning and should master. Given the complementarity of thematic patterns and content, teachers and students can be classified and matched according to their different characteristics, and then adapt the appropriate teaching model. For example, in the process of teaching practice, it is possible to arrange active students (such as marketing, international trade, etc.) with strong activities, good organizational skills, good oral English and proactive thinking, and to arrange fluency in grammatical structure. The teachers who are relatively poor in spoken language and familiar with the grammar structure are arranged to teach rigorous, ethical students (such as accounting students). Because the specific conditions of teachers and students in various universities vary widely and cannot be generalized, the above match is only based on the characteristics of teachers and students in the author's school. In addition, according to the teacher's mastery of teaching theory and teaching methods, the theme model and content practice can also be used interchangeably in the teaching process of college English common courses.

\subsection{Combination of CBI Teaching Mode and other Teaching Modes.}

Stryker \& Leaver pointed out that CBI is a true sense of a comprehensive foreign language education concept. Language cannot be separated from the content of the information it delivers. Any form of language teaching must be content-based. Therefore, CBI as a language teaching concept is suitable for any form of language teaching. This universality of the CBI concept determines its compatibility with any other language teaching method and pattern theory. Other language teaching methods and modes, although the operating rules and applicable language teaching fields are all different, can all be combined with the CBI concept to improve the teaching effect. The following discussion of the combination of several non-CBI teaching methods and modes that are currently common.

The communicative approach is mainly applicable to English listening and speaking teaching, and the most essential theoretical basis for communicative teaching is the CBI concept. Understand this point, the communicative teaching of College English Listening and Speaking course can be combined with CBI's selection of teaching materials, the determination of communication themes, and other related requirements, so that teaching activities become more vivid and interesting, close to the needs of students, accepted by students. The same combination of situations, the same combination of results also appear in the combination of task-based teaching and CBI, task-based teaching under the guidance of CBI theory, not only for listening and speaking teaching, but also suitable for reading, writing, translation and other English teaching areas .

The "College English Course Teaching Requirements" promulgated by the Ministry of Education in 2007 proposes that we must make full use of multimedia network technology and adopt new teaching modes to improve the single classroom teaching model that focuses on teaching. Afterwards, the reform of the college English teaching model officially went into a new direction. So far, although a new round of reforms in universities around the world has spawned a variety of new teaching modes, these new teaching modes (collectively referred to as the "new mode" below) are nothing more than the following three main features, shown in Figure 1: (1) Student-centered, focusing on the cultivation of students' self-learning ability; (2) Emphasis on multi-level and three-dimensional teaching model, teacher's teamwork, student cooperative learning and individualized learning. (3) Supported by modern information technology, Achieve the goal of 
reform. The combination of these characteristics of the new model and CBI theory can produce the advantages of superposition and complementary advantages, further enrich the theoretical system of the new model, and strengthen the teaching efficacy of the new model. First, the CBI provides practical and concrete solutions and methods for the new model to achieve its reform goals. The theoretical core of the CBI model is to enable students to acquire language in thematic activities, which in itself embodies the new model ideas of "student-centered," "cooperative learning," "self-learning," and "self-development." The CBI's more detailed and effective rules and principles in the organization of activities and the choice of topics are powerful guarantees for the implementation of these ideas. Second, the CBI provides theoretical support for the multi-level and three-dimensionality of the new model. The multi-level and three-dimensional connotation in the new model is rich in content. One of them refers to the combination of multiple teaching methods and teaching modes and avoiding weaknesses. The new model is not a single teaching mode in the traditional sense, but a fusion of many teaching modes. The theory and rules of different teaching methods and teaching modes are inevitably inconsistent. It is not easy to choose between the different teaching methods and teaching modes. It requires a theoretical platform that can guide all teaching methods and teaching modes. The universal characteristics of CBI theory make it can undertake this task. Since all language teaching is content-based, then based on what content, to what extent is based on content, and how based on content becomes the theory to explore and determine the status and role of many teaching methods and teaching models in the multi-level three-dimensional new model. From the perspective, therefore, CBI becomes the theoretical exchange platform for all teaching methods and teaching models. Third, the application of modern information technology in the new model can, to a large extent, provide contextual support for the CBI model. Compared with the country of origin of the CBI (United States), the biggest congenital deficiency of our English teaching lies in the absence of natural teaching context. This is very detrimental to English teaching and is not conducive to the development of CBI theme activities. The application of modern information technology such as multimedia and networking provides the most realistic English virtual context for CBI teaching in the college English public course.

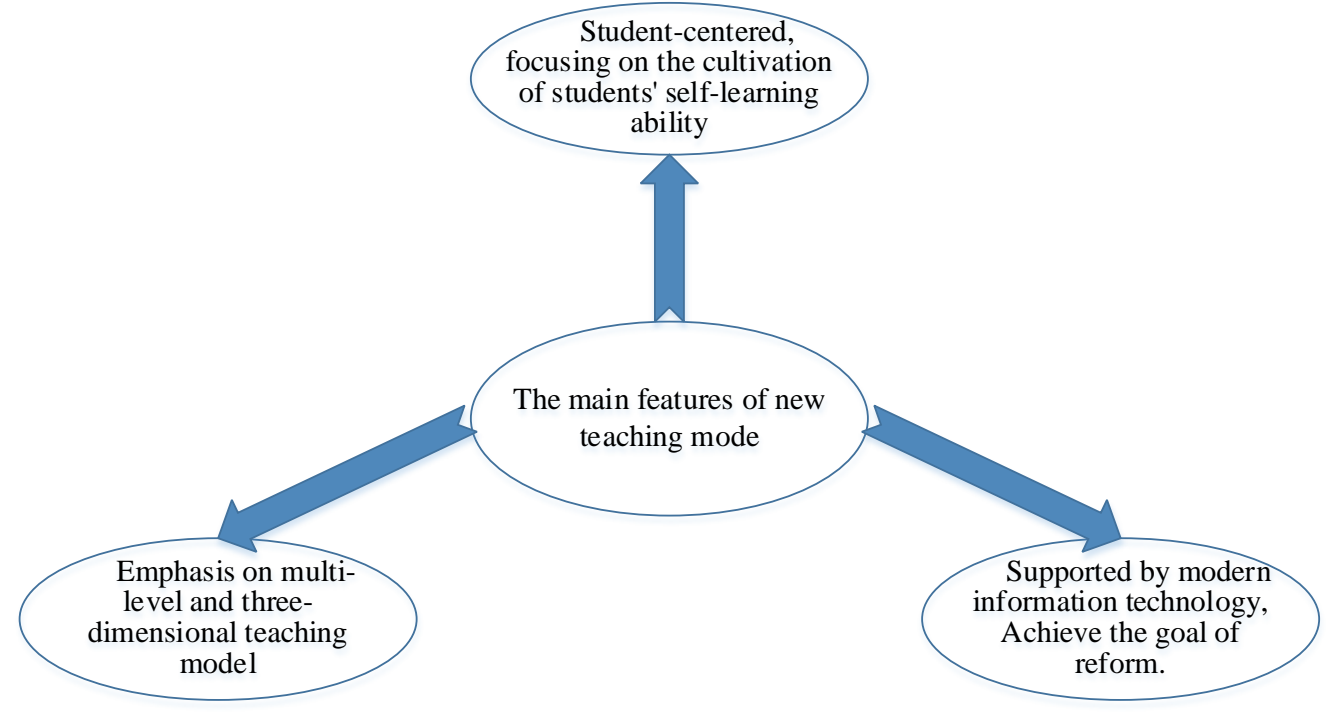

Figure 1. The main features of new teaching mode

\section{Conclusion}

The contemporary teaching reform is trying to explore a comprehensive and efficient teaching mode for the teaching of college English common courses. Using the CBI as a theoretical platform to absorb numerous teaching methods and modes and designing a comprehensive and complete model system is only one aspect of ensuring the success of the new round of teaching reform. Although the new mode under the CBI concept is the historical development trend of college 
English teaching reform, the successful implementation of the new mode requires social and school environmental conditions. It requires the cooperation of teachers and students, involving a variety of teaching resources and management resources. Reconfigured, coupled with the current lack of understanding of the CBI in the education sector in China. This mode results in a flowering result that still requires the joint efforts of all sectors of society.

\section{References}

[1] Zhou Y. College English CBI Course Teaching: Module Cognition and Process Perspective [J]. Journal of Hebei Radio \& TV University, 2016, 1: 23-25.

[2] Liu C J. CBI Network Courses for College English Based on MOOCs [J]. Journal of Hubei Radio \& Television University, 2015, 5: 1-3.

[3] Shen X Y, Zeng Q Y. On the Construction of the Course of Further Study of College English under the Guidance of CBI Theory [J]. Journal of Anhui University of Technology, 2010, 3: 14-15.

[4] Duan S J, Liu Q, Fang J Z. Research on the CBI Model in the Extracurricular Reading of the College English Major Primary Phase[J]. Journal of Kunming University, 2010, 2: 26-29. 